\title{
Computer-Based Learning Objects in Healthcare: The Student Experience
}

Holly Blake, University of Nottingham

Contact: holly.blake@nottingham.ac.uk

\begin{abstract}
Web-based computer learning objects, such as Reusable Learning Objects (RLOs), are be- coming more commonplace in nursing and medical education. However, evaluation of RLOs specifically has been limited. The aim of the study was to determine how RLOs impact on the student learning experience and to compare the use and evaluation of RLOs by nursing and medi- cal students. An online questionnaire survey was completed by 233 students (163 nursing and 73 medical). RLOs were more commonly used by nursing students than medical students. Students in both disciplines valued RLOs for flexibility of learning, as revision aids, and to supplement classroom-based learning. Nursing and medical students have different learning needs, and developing materials at the right level of learning is important. Barriers to the use of RLOs included lack of IT competence, technical difficulties, and lack of staff awareness of computer-based learning aids.
\end{abstract}

KEYWORDS: technology, e-learning, higher education, students 


\section{Introduction}

The United Kingdom National Health Service (NHS) is undergoing radical changes with the initiation and implementation of the NHS National Programme for Information Technology. Increasingly, technology is used for health communications, healthcare delivery, and patient monitoring (Blake, 2008a; Blake, 2008b). However, practicing nurses use electronic resources in the workplace less frequently than physicians (Estabrooks, O’Leary, Ricker, \& Humphrey, 2003), although IT skills are required by both groups for effective decision-making and care delivery (McNeil et al., 2003).

Changes in the preparation of health professionals are required to incorporate new and innovative teaching methods as higher education institutions respond to technological advances in health care. Accordingly, information and communication technologies are increasingly used in learning and teaching to supplement learning and catalyze the rate of knowledge transfer (Adams, 2004; Blake, 2009; Mehanna, 2004).

Significant funds have been invested nationally in the development of reusable learning objects (RLOs) for healthcare disciplines through the Centre for Excellence in Teaching and Learning in Reusable Learning Objects (RLO- CETL) (http://www.rlo-cetl.ac.uk). RLOs are "web-based interactive chunks of e-learning designed to explain a stand-alone learning objective" (RLO-CETL). They are available for a growing range of subject areas and often promoted in nursing, although less so in medicine where computer-aided learning packages are more commonly accessed. RLOs are commonly supplements to learning, with some used as stand-alone revision aids and some integrated within classroom learning. The level of interactivity and use of video or audio clips varies. 
Evaluation of learning outcomes of RLOs tends to be on an individual RLO basis and dependent on the educator. Little is known about students' access to RLOs and their views on the usefulness of the tools. Therefore, a study was developed to investigate students' use of RLOs.

\section{LITERATURE REVIEW}

In broad terms, e-learning is learning which is assisted by interactive electronic technology, offline or online (Beetham, 2002). E-learning overcomes many traditional barriers to education, and offers advantages such as increased opportunities for continuing professional development, flexibility of learning, asynchronous teachinglearning, and enhanced curriculum accessibility. This is particularly important in healthcare where students often balance their learning with shift rotations, overtime work, and family commitments (Blake, 2009). Electronic education methods support selfdirected learning, students' acquisition of skills and confidence in using information technology, a transition from classroom to independent learning (Smith, 2002; Thiele, 2003), and individually paced learning. E-learning can be time-efficient for teachers, freeing them to focus on learners' educational needs (Berke \& Wiseman, 2004).

Computer-based learning objects have potential to enrich the learning process, although in practice, development can be content-focused, costly, and labour-intensive. However, the process of learning is important. Therefore, the quality of instructional design is key, involving a sound knowledge of education, an understanding of learning theory, and an affinity with modern technologies (Maxwell, Doherty, \& Jones, 2005). Essential in the 
development of computer- based learning tools is the end-users' perspective, since this determines use and acceptability of such tools, and whether effective learning takes place (Moisio, Markkula, \& Smeds, 2003).

\section{Learners and E-Learning}

Nursing students have ambivalent feelings towards computerized technologies (Thompson et al., 2001), a reticence to adapt to technological innovations (Adams \& Timmins, 2006), and lower IT skills at program entry than undergraduate medical students (Seago, Schlesinger, \& Hampton, 2002). Evidence about the impact of computerized teaching tools on student satisfaction and learning is contradictory and perhaps indicative of variations in student learning styles within study samples (Mitchell,

Ryan, Carson, \& McCann, 2007). In some studies, e-learning has been reported to encourage independent learning (Thiele, 2003), enhance student satisfaction (Jeffries, 2001; Maag, 2004), create greater stimulation in learning compared with traditional lectures (Woo \& Kimmick, 2000), and enhance critical and reflective thinking (Ali, Hodson- Carlton, \& Ryan, 2004). Further, increased frequency of use of online materials by nursing students is associated with higher assignment marks (Mitchell et al.). Conversely, lower evaluation scores for web-based learning compared with traditional classroom learning (Buckley, 2003), and lower satisfaction with fully web-based learning courses compared with web-supplemented traditional forms of learning (Kearns, Shoaf, \& Summey, 2004) have been reported.

There has been exploration of the student learning experience in relation to e-learning in general (Atack \& Rankin, 2002; Chang, Tseng, Hsaio, \& Wang, 2003, Gill, 2007), and 
the specific learning outcomes of particular reusable learning tools in certain health topics (e.g., Conroy, 2007; Leonardi-Bee, 2007). However, the accessibility, use, and impact of RLOs on the student learning experience in nursing and medicine have not yet been fully investigated.

\section{STUDY PURPOSE}

The primary aim of the study was to assess student use of reusable learning objects their impact on the student learning experience. A secondary aim was to compare the use and evaluation of RLOs between students from the disciplines of nursing and medicine.

\section{METHODS}

Ethical approval was granted for this cross-sectional questionnaire study by the local Medical School Ethics Committee in March 2008. Approval for accessing medical and nursing students was granted by the participating Faculty.

\section{Questionnaire Survey}

The questionnaire is an existing evaluation tool developed by RLO- CETL, to be completed by students who have used one or more RLOs in their module or course of study. Questionnaire items included demographic data, self- reported computer use, access to RLOs, use of reusable RLOs, and matters related to learning. Items were mostly closed questions ('tick-box') with opportunity for free text responses to expand on responses. 


\section{Procedures}

Following a brief pilot survey resulting in some minor amendments, an invitation to access a link to a web-based online structured questionnaire survey was sent by e-mail to all nursing and medical students, together with an explanation of the purpose and voluntary nature of the survey. A link to the survey was also placed on the students' Networked Learning Environment, the student intranet Portal, and Faculty websites. Completion of the survey was voluntary and anonymous, and no identifying demographic data were requested. Respondents were asked to identify whether they were a nursing or medical student. After four weeks, reminders were sent by email to all students. Data were analysed using SPSS Version 15.0.

\section{RESULTS}

\section{Demographic data}

Of the 542 students who viewed the survey, 233 (43\%) completed it. There were 160 nursing students, $143(89.4 \%)$ female and 17 (10.6\%) male. Nursing students were from all four years of study (year $1=40 \%$, year $2=28.8 \%$, year $3=26.9 \%$, year $4=4.4 \%$ ). There were 73 medical students, 45 (61.6\%) female and 28 (38.4\%) male. Medical students were from all five years of study (year $1=61.6 \%$, year $2=9.6 \%$, year $3=15.1 \%$, year $4=9.6 \%$, year $5=4.1 \%)$.

The ages of nursing students ranged from 17 to 59 years $(M=27.54, S D=8.88)$ whereas the medical students were 18 to 43 years old $(M=21.58, S D=.4 .59)$. Nursing students were significantly older than medical students $(t=5.41, d f 227, p<0.001)$. 


\section{Self-reported Computer Use}

There were no significant differences between medical and nursing students' reported access to the web. However, there was a significant difference in reported computer

confidence $\left(\chi^{2}=6.8\right)$ : nursing students $(17.5 \%)$ were three times more likely to report low confidence than medical students (5.5\%) and medical students (94.5\%) were more likely to report higher confidence than nursing students (82.5\%). Despite this, nursing students (76.2\%) were more likely to have used RLOs than medical students $(13.7 \%)\left(x^{2}=79.87\right)$.

\section{Access to learning objects}

Most students (83.7\%) heard about RLOs from lecturers or module leaders with a minority hearing about them from other students (5.2\%), the course handbook (3\%), this survey (3\%), or by other methods such as web browsing. Students most commonly accessed RLOs at the beginning or during a course or module, or before an assessment. A minority reported technical difficulties in accessing the RLOs. Nursing students highlighted a small number of concerns including titles not indicative of RLO content, inadequate resources at one learning centre (e.g., no sound), and slow internet access. Medical students did not identify any particular technical difficulties except for time for the RLO to load. Computer access, computer confidence and use of RLOs for nursing and medical students are presented in Table 1. 


\section{Table 1}

Frequency and Percentage of Student Computer Access, Computer Confidence, and RLO Use

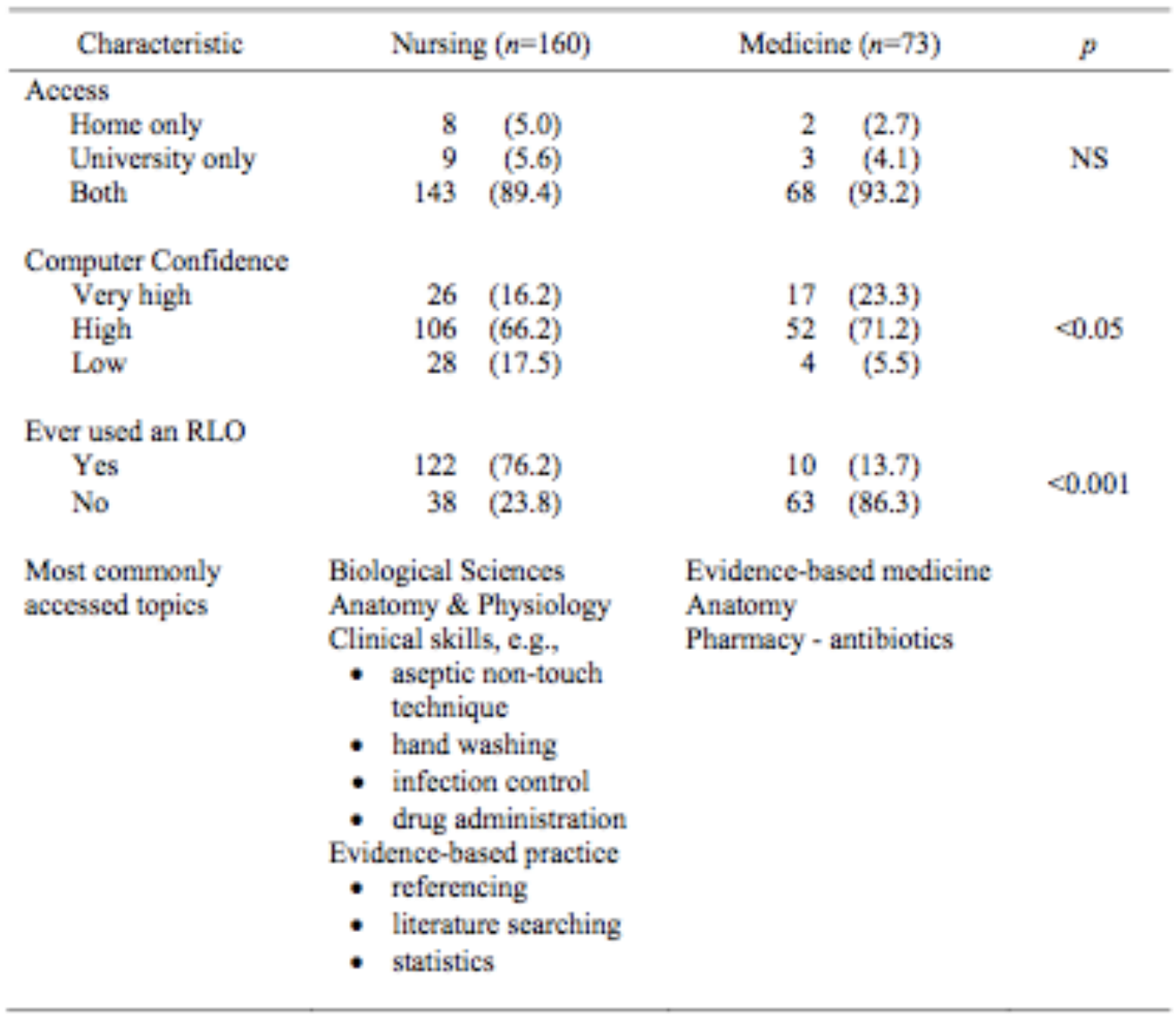

\section{Learning with Reusable Learning Objects}

Students who had used an RLO responded to items about the learning experience.

Overall, responses were positive with $94 \%$ reporting they would use RLOs again. See

Table 2 for the full results. In Table 3 students' responses to evaluation of various elements of the RLOs are presented. 


\section{Table 2}

Frequency and Percentage of Responses to Evaluation Items about RLOs $(N=152)$

\begin{tabular}{|c|c|c|c|c|c|c|c|c|}
\hline \multirow{2}{*}{$\begin{array}{l}\text { RLO Evaluation } \\
\text { Item }\end{array}$} & \multicolumn{2}{|c|}{$\begin{array}{c}\text { Strongly agree } \\
n(\%)\end{array}$} & \multicolumn{2}{|c|}{$\begin{array}{l}\text { Agree } \\
n(\%)\end{array}$} & \multicolumn{2}{|c|}{$\begin{array}{c}\text { Disagree } \\
n(\%)\end{array}$} & \multicolumn{2}{|c|}{$\begin{array}{c}\text { Strongly disagree } \\
n(\%)\end{array}$} \\
\hline & 38 & $(28.4)$ & 93 & $(69.4)$ & 3 & (2.2) & 0 & $(0) \dagger$ \\
\hline Easy to navigate & 52 & $(34.2)$ & 93 & $(61.2)$ & 7 & (4.6) & 0 & (0) \\
\hline $\begin{array}{l}\text { Introduced new } \\
\text { concepts/terms } \\
\text { clearly }\end{array}$ & 28 & $(21.1)$ & 95 & (71.4) & 10 & (7.5) & 0 & (9) \\
\hline $\begin{array}{l}\text { Would } \\
\text { recommend to } \\
\text { my peers }\end{array}$ & 48 & $(36.1)$ & 80 & $(60.2)$ & 5 & $(3.7)$ & 0 & $(0)$ \\
\hline $\begin{array}{l}\text { Would like to } \\
\text { see more RLOs } \\
\text { to support } \\
\text { modules }\end{array}$ & 60 & $(44.8)$ & 62 & $(46.3)$ & 10 & (7.5) & 2 & (1.4) \\
\hline $\begin{array}{l}\text { At the right level } \\
\text { for my stage in } \\
\text { the course }\end{array}$ & 21 & $(15.8)$ & 100 & $(75.2)$ & 12 & $(9.0)$ & 0 & $(0)$ \\
\hline $\begin{array}{l}\text { Complement } \\
\text { other teaching } \\
\text { on the course }\end{array}$ & 25 & (18.8) & 96 & $(72.2)$ & 12 & $(9.0)$ & 0 & $(0)$ \\
\hline $\begin{array}{l}\text { Enjoy learning } \\
\text { from RLOs }\end{array}$ & 35 & (26.1) & 86 & $(64.2)$ & 12 & $(9.0)$ & 1 & $(0.8)$ \\
\hline $\begin{array}{l}\text { I learn better } \\
\text { from RLOs than } \\
\text { books }\end{array}$ & 24 & (18.1) & 52 & (39.1) & 5 & $(3.7)$ & 0 & $(0)$ \\
\hline $\begin{array}{l}\text { I learn better } \\
\text { from RLOs than } \\
\text { lectures }\end{array}$ & 9 & $(6.7)$ & 39 & (2.9) & 77 & (55) & 10 & (7.4) \\
\hline
\end{tabular}


Table 3

Frequency and Percentage of Responses to Items about the Value of RLO Elements $(N=134)$

\begin{tabular}{|c|c|c|c|c|c|c|c|c|}
\hline RLO Element & Im: & $\begin{array}{l}\text { ery } \\
\text { ortant } \\
(\%)\end{array}$ & $\operatorname{Imp}$ & $\begin{array}{l}\text { ortant } \\
\text { (\%) }\end{array}$ & $\begin{array}{r}\text { No } \\
\text { Im! } \\
n \\
\end{array}$ & $\begin{array}{l}\text { Very } \\
\text { ortant } \\
(\%)\end{array}$ & $\begin{array}{c}\text { Not } \\
\text { Impo } \\
n(\end{array}$ & $\begin{array}{l}\text { at all } \\
\text { irtant } \\
\% \text { ) }\end{array}$ \\
\hline $\begin{array}{l}\text { Visual, e.g. } \\
\text { video/animation }\end{array}$ & 59 & $(44.0)$ & 64 & $(47.8)$ & 9 & $(6.7)$ & 2 & (1.5) \\
\hline $\begin{array}{l}\text { Audio or } \\
\text { Commentary }\end{array}$ & 32 & (23.9) & 53 & (39.6) & 40 & $(29.9)$ & 9 & $(6.7)$ \\
\hline Interactivity & 62 & $(46.0)$ & 61 & $(45.6)$ & 7 & $(5.3)$ & 4 & (3.0) \\
\hline $\begin{array}{l}\text { Assessments or } \\
\text { Exercises }\end{array}$ & 68 & $(50.7)$ & 56 & $(41.8)$ & 5 & (3.7) & 5 & (3.7) \\
\hline Online Access & 102 & $(76.0)$ & 25 & $(18.7)$ & 5 & $(3.7)$ & 2 & (1.5) \\
\hline
\end{tabular}

Students reported a range of aspects of relating to ease of access and the ability to reflect back on learning at a convenient time and location: "RLOs can be reviewed as often as required, whenever required" and, "They are simple to understand, and you can absorb information at your own pace". The ability to access them from home, or whilst on placement, seemed an important element in order that students could work through materials at a pace comfortable to them. One said, "I have commitments outside of the university and have to fit in my study when I can. Knowing that there are RLOs available means that I can go over a topic without having to contact my tutor with basic questions which would make me feel a bit silly".

The value of RLOs as an alternative and supplementary mode of learning was recognised: "the interactivity...gives a different perspective" and "I learn better with animation and interactive elements". One student said that amalgamating visual and 
auditory information made the materials understandable to a larger number of people, and stated: "with the combination of visual and audio materials I picked things up faster".

One student, disclosed a learning disability, relied on RLOs as an effective enhancement to lecture materials, which provided 'manageable chunks' of learning. Others valued the fact that RLOs provided accurate 'notes'. Many reported that RLOs were helpful as revision aids or as a method of consolidating learning undertaken in the classroom. One stated, "They (RLOs) give easy explanations of topics I find complicated. You can play them over and over again if you don't understand the concepts or want some revision". Many recognised the value of RLOs for 'repeatability' and one noted that RLOs were easier to understand since, "in a lecture, it can be very confusing to move on when you haven't grasped the subject". Some valued the ability to test their own knowledge and learning: "I like there to be an assessment at the end so I can see what I have learnt" and "using online exercises can test my knowledge by working through examples and then seeing where I went wrong”.

The relevance of materials was raised by those who noted the importance of integrating RLOs directly with course content: "If it is targeted for our course, then we can be confident that all the content is appropriate." Some commented that RLOs could occasionally be at the wrong level, either "too complicated" or "fall below expectations of learning needs", and some said they would have benefited from additional direction to further reading materials. Difficulties were identified in locating the desired RLOs. Barriers to access were poor organisation of RLOs online and occasional technical difficulties. Some students reported a lack of confidence with computer use, although there was acknowledgment that computer competence is necessary and would "help me 
to develop my IT skills".

An inability to ask questions was identified as a negative aspect of computer-based learning, and amongst some students there was a lack of motivation to use materials that were not mandatory for the course. Further, students highlighted that knowledge of RLOs was not consistent amongst teaching staff: 'I asked my tutor about them and she didn't know what they were...not all the lecturers can tell you what is available'. However, the most common feedback was that more RLOs are required to support a wider range of subjects: "there are simply not enough of them". The majority of comments were positive and suggested that students valued RLOs: "almost all of the RLOs I have visited I will access again".

\section{DISCUSSION}

This study explored the use of online RLOs by nursing and medical students. Many nursing students confidently used RLOs (when compared with a smaller group of medical students) and despite some barriers, found them useful as learning tools, particularly due to the online access, self-assessment capabilities, and interactivity. E-learning seems to be well-accepted by the majority of healthcare students who appreciated flexibility and choice in learning opportunities. Nursing students reported concerns relating to IT skills; some medical students reported concerns about pedagogical expectations for RLOs and ensuring content is matched to the level of study. Students saw e-learning as supplementing rather than replacing traditional methods of learning in nursing and medicine. 


\section{IT Confidence, Access, and Flexible Learning}

Barriers to the use of RLOs can be readily addressed. Students suggested increasing organization of RLOs online so materials could be more readily located and increasing awareness about their availability amongst staff. Nevertheless, accessing and using RLOs is also dependent on IT confidence and this was identified as a barrier amongst nursing students but not medical students; this is comparable with other research suggesting that medical practitioners are more comfortable in, or certainly report greater use of IT than nurses (Adams \& Timmins, 2006; Estabrooks, et al., 2003). Since healthcare delivery increasingly relies on information technology, a lack of IT skills amongst healthcare students, particularly of nurses, is of concern (Adams \& Timmins). Although RlOs and other computer-assisted learning techniques are becoming more commonplace within educational environments, study findings highlight the need to raise awareness about these tools amongst both staff and students, and to provide training opportunities for staff so that RLOs are appropriately integrated within the curriculum. This will require ongoing support and mentoring for development and delivery, technological training, and incentives for staff involvement (Blake, 2009). Staff training may also ensure that technical aspects of such tools are improved whilst still supporting pedagogical aspects of learning. For the students, particularly in the nursing profession, improving student confidence in e-learning via education and training will be essential for encouraging further use of these methods. Some authors have suggested that simply engaging in elearning can itself serve to increase computer competence (Atack \& Rankin, 2002).

Students in this study identified the benefits of RLOs for flexible learning, either to supplement traditional methods of learning, consolidate classroom teaching or for 
revision aids, and to provide peace of mind knowing that materials provided in the classroom could be accessed again at a later date. Authors have previously identified the need for more flexibility and accessibility in educational provision in healthcare subjects (Clark \& Robinson, 1994) and that online learning may be advantageous for healthcare students who benefit from flexibility of time and location for knowledge acquisition (Blake, 2009). Certainly, computer-based learning has been shown to be the preference for qualified health professionals undertaking continuing professional development (e.g. Chang, et al., 2003; Gill, 2007).

\section{Learning with Learning Objects}

E-learning has been described as a 'revolution in education' (Ruiz, Mintzer, \& Leipzig, 2006) and research has shown that learning with e-learning tools can be effective even for clinical decision-making and practice learning (Atack, 2003; Atack \& Rankin, 2002; Niederhauser, Bigley, Hale, \& Harper, 1999). Participants in this study held predominantly positive attitudes towards RLOs and they felt the need to increase the range of subjects available. Despite positive attitudes towards RLOs, like staff in previous surveys (Blake, 2009), these students viewed the e-learning tools as supplementary learning materials to complement traditional teaching. Nevertheless, having access to supplementary tools such as RLOs not only integrates e-learning into healthcare education and improves IT skills, but allows learning to be individualized and teaching to be multifaceted to account for varying learning styles and preferences.

There was some variation in student expectations of e-learning tools, and differences in training and support needs between nursing and medical students. However, although 
confidence and competence to use e-learning tools may vary, it is clear that e-learning materials need to be visually stimulating and interactive rather than simply informational for students to engage with the pedagogy effectively (Song \& Kidd, 2005). RLOs also need to be relevant to level of study and at the appropriate level of complexity for the learners. Again, there may be differences between nursing and medicine in expectations and therefore it is recommended that they are developed specific to a discipline, or if interdisciplinary, they need to be developed by a multiprofessional team to ensure content is appropriate to target differences in learning levels.

\section{Study Limitations and Implications for Further Research}

There are a number of limitations to this study. Firstly, knowledge of student use of computer-based learning tools is limited to those who responded to the online survey. It may be that the most 'computer-competent' students completed the survey and thus, we may know little of the attitudes towards e- learning held by those less competent or confident in online technologies. However, a large proportion of those who clicked on the web link did complete the survey and the response rate overall was higher than other elearning surveys of healthcare students (e.g. Docherty \& Sandhu, 2006) and therefore, was perceived to be high enough to develop a picture of attitudes towards e-learning in the healthcare student population. Nevertheless, the findings may not be representative of non-responders from these disciplines, particularly in medicine where only a small number of students had engaged with RLOs.

Further, the survey used the term reusable learning object (RLO) to reflect one of the computer-based learning tools frequently used within the Faculty. Due to developing e- 
learning strategy within the Faculty, a large proportion of teaching staff in nursing are currently aware of RLOs regardless of whether they actually use them in teaching or not (Blake, 2009). Comparable information for medicine is not available. However, some students may not know the term and may have reported that they had not used RLOs when, in fact, they were simply not familiar with the terminology. This may be particularly relevant for students in medicine who may be more familiar with the term computer-aided learning. As well the nursing school's recent investment in e- learning and RLO development may have made the term more familiar to nursing students. As well, it must be recognized that there are many e-learning tools and RLOs represent just one form of these.

This study examined responses to RLOs in general, although investigating student responses to specific RLOs would have allowed for identification of specific elements that students found valuable (e.g. RLOs vary in level of interactivity). This warrants further investigation.

Although these findings are unique to students' perceptions of RLOs rather than elearning materials in general, the issues raised may be relevant to other e-learning modalities. Whilst this study sheds light on healthcare students' use of RLOs and their perceptions of e-learning as method of learning, qualitative study would provide more indepth analysis. Further research should quantify the impact of RLO use on educational attainment, and also investigate whether this form of learning can serve to improve practice skills and quality of patient care as well as theory-based subjects.

\section{CONCLUSION}


Healthcare students were positive about RLOs and this form of e-learning should be acknowledged as a formal learning tool, complementing traditional learning resources and providing individualized learning and flexibility. Education and training should be provided for staff in successful development and integration of RLOs into curriculum. Developing and embedding materials into education and clinical practice puts increased demands on educator's time, which must be recognized and supported. Consistent with previous studies, it is recommended that technical support and guidance be provided for students who lack confidence or for whom computer skills may be below the expected 'norm' (Mitchell et al., 2007). E-learning materials need to be easily accessible and widely promoted as a source of learning. They need to be interactive, engaging, and appropriately matched to course materials and to learning needs of the target population. Attention needs to be paid to the underpinning pedagogy and desired learning outcomes.

\section{Acknowledgments}

The author thanks Heather Wharrad for her contribution to online data collection; and Saoirse O'Sullivan and Louise Cook for their role in gaining ethical approval and comments on study design.

\section{REFERENCES}

Adams, A. M. (2004). Pedagogical underpinnings of computer-based learning. Journal of Advanced Nursing, 46, 5-12. doi:10.1111/J.1365-2648.2003.02960.X 
Adams, A., \& Timmins, F. (2006). Student's views of integrating web-based learning technology into the nursing curriculum: a descriptive survey. Nurse Education in Practice, 6, 12-21. doi:10.1016/j.nepr.2005.05.005

Ali, N. S., Hodson-Carlton, K., \& Ryan, M. (2004). Students' perceptions of online learning: implications for teaching. Nurse Educator, 29, 111-115. doi:10.1097/00006223200405000-00009

Atack, L. (2003). Becoming a web-based learner: Registered nurses' experiences. Journal of Advanced Nursing, 44, 289-297. doi: 10.1046/J.1365-2648.2003.02804.X

Atack, L., \& Rankin, J. (2002). A descriptive study of registered nurses' experiences with web-based learning. Journal of Advanced Nursing, 40, 457-465. doi: 10.1046/J.13652648.2002.02394

Beetham, H. (2002). Understanding eLearning TechLearn Workshop, July. Retrieved March 28, 2010, from www.http://techlearn.ac.uk/NewDocs/elearning.doc

Berke, W. J., \& Wiseman, T. L. (2004). The e-learning answer [electronic version]. Critical Care Nurse, 24, 80-84.

Blake, H. (2008a). Innovation in practice: Mobile phone technology in patient care. British Journal of Community Nursing, 13, 160-165.

Blake, H. (2008b). Using technology in health promotion intervention. In: M.R. Blakely, S.R. Timmons (Eds.), Lifestyle and Health Research (pp.17-76). New York: NovaScience Publishers, Inc. 
Blake, H. (2009). Staff perceptions of e-learning in healthcare teaching delivery. Learning in Health and Social Care, 8, 223-23. doi:10.1111/J.1473- 6861.2009.00213

Buckley, K. M. (2003). Evaluation of classroom-based web-enhanced and web- based distance learning nutrition courses for undergraduate nursing. Journal of Nursing Education 42, 367-370.

Chang, W. Y., Tseng, I. J., Hsaio, F. H., \& Wang, M.Y. (2003). Continuing education needs and barriers for public health nurses in Aboriginal townships for Taitung, Taiwan. Journal of Nursing Research, 11, 295-302.

Clark, E., \& Robinson, K. (1994). Open learning: the state of the art in nursing and midwifery. Nurse Education Today, 14, 257-263. doi:10.1016/0260- 6917(94)90135-X

Conroy, S. (2007). Evaluation of computer-based teaching of rehabilitation concepts.

Retrieved April 14, 2010, from University of Nottingham website: http://www.nottingham.ac.uk/pesl/resources/elearning/evaluatx053/

Docherty, A., \& Sandhu, H. (2006). Student-perceived barriers and facilitators to elearning in continuing professional development in primary care. Education for Primary Care, 17, 343-353.

Estabrooks, C. A., O'Leary, K. A., Ricker, K. L., \& Humphrey, C. K. (2003). The internet and access to evidence: how are nurses positioned? Journal of Advanced Nursing, 42, 73-81. doi:10.1046/j.1365-2648.2003.02581.x

Gill, A. (2007). E-learning and professional development - never too old to learn. British 
Journal of Nursing, 16, 1084-1088.

Jeffries, P. R. (2001). Computer versus lecture: a comparison of two methods of teaching oral medication administration in a nursing skills laboratory. Journal of Nursing Education, 40, 323-329.

Kearns, L. E., Shoaf, J. R., \& Summey, M. B. (2004). Performance and satisfaction of second-degree BSN students in web-based and traditional course deliver environments. Journal of Nursing Education, 43, 280-284.

Leornardi-Bee, J. (2007). Development and evaluation of a re-usable learning tool to supplement didactic lectures. Retrieved April 14, 2010, from University of Nottingham website: http://www.nottingham.ac.uk/pesl/resources/elearning/developm498/

Maag, M. (2004). The effectiveness of an interaction multimedia learning tool on nursing students' math knowledge and self-efficacy. CIN: Computers, Informatics, Nursing, 22, 26-33. Retrieved from http://journals.lww.com/cinjournal/toc/2004/01000

Maxwell, I., Doherty, I., \& Jones, N. (2005, August 4-7). E-learning: learning led and technology enabled. Special Issue of IJCIM Proceedings of the Second International Conference on eLearning for Knowledge-Based Society, Bangkok, Thailand. Retrieved Feb 02, 2010 from:

http://www.elearning.au.edu/research/elearning_conference_2005/Proceedi ng2005\%20and\%20Book/PP19.pdf

McNeil, B. J., Elfrink, B. L., Binckford, C. J., Pierce, S. T., Beyea, S. C., Averill, C., \& Klappenbach, C. (2003). Nursing information technology, skills, and preparation of 
student nurses, nursing faculty and clinicians: A U.S. Survey. Journal of Nursing Education, 42, 341-349.

Mehanna, W. N. (2004). E-pedagogy: the pedagogies of e-learning. Research in Learning Technology, 12, 279-293. Retrieved from:

http://dx.doi.org/10.1080/0968776042000259582

Mitchell, E. A., Ryan, A., Carson, O., \& McCann, S. (2007). An exploratory study of web-enhanced learning in undergraduate nurse education. Journal of Clinical Nursing, 16, 2287-2296. doi:10.1111/j.1365- 2702.2006.01931.x

Moisio, A., Markkula, M. J., \& Smeds, R. (2003). E-learning lessons learnt from a student perspective: a cross-case comparison between public and private organizations. Paper presented at the International Workshop of the IFIP WG 5.7: Experimental Interactive Learning in Industrial Management, Aalborg, Denmark. Retrieved Oct 09, 2009 from http://www.simlab.hut.fi/publications/publications.htm

Niederhauser, V. P., Bigley, M. B., Hale, J., \& Harper, D. (1999). Cybercases: An innovation in internet education. Journal of Nursing Education, 38, 415-418.

Ruiz, J. G., Mintzer, M. J., \& Leipzig, R. M. (2006). The impact of e-learning in medical education. Academic Medicine, 81, 207-212. doi:10.1097/00001888-200603000-00002

Seago, B. L., Schlesinger, J. B., \& Hampton, C. L. (2002). Using a decade of data on medical student computer literacy for strategic planning. Journal of the Medical Library Association, 90, 202-209. Retrieved April 10, 2010 from http://www.ispub.com/journal/the_internet_journal_of_medical_informatic 
s/volume_5_number_1_52/article/assessing-computer-literacy-and-attitude-towards-elearning-among-final-year-medical-students.html

Smith, M. A. (2002). Efficacy of a web-enhancement on student technology skills. Online Journal of Nursing Informatics, 6, 6-12. Retrieved Nov 07, 2010 from http://ojni.org/1002/smith.htm.

Song, H., \& Kidd, T. (2005). Findings of aspects affecting student's perceptions regarding instructional quality of online courses: an empirical study. In G. Richards (Ed.): Proceedings of World Conference on E-Learning in Corporate, Government, Healthcare and Higher Education Chesapeake, VA. Retrieved Nov 07,2010 from http://www.editlib.org/?fuseaction=Reader.ViewAbstract\&paper_id=2155 6

Thiele, J. E. (2003). Learning patterns of online students. Journal of Nursing Education, 42, 364-366.

Thompson, C., McCaughan, D., Cullum, N., Sheldon, T., Mulhall, A., \& Thompson, D. R. (2001). The accessibility of research-based knowledge for nurses in the United Kingdom acute care settings. Journal of Advanced Nursing, 36, 11-22. doi:10.1046/j.1365-2648.2001.01938.x

Woo, M. A., \& Kimmick, J. V. (2000). Comparison of Internet versus lecture instructional methods for teaching nursing research. Journal of Professional Nursing, 16, 132-139. doi:10.1053/PN.2000.5919 